\title{
A Genetic Map of Squash (Cucurbita sp.) with Randomly Amplified Polymorphic DNA Markers and Morphological Markers
}

\author{
Rebecca Nelson Brown and James R. Myers ${ }^{1}$ \\ Department of Horticulture, ALS 4017, Oregon State University, Corvallis, OR 97331
}

\begin{abstract}
AdDitional INDEX words. Cucurbita pepo, Cucurbita moschata, tropical pumpkin, fruit color, quantitative trait loci, QTL, RAPD

ABSTRACT. A molecular and morphological marker map would improve our knowledge of $C$ ucurbita genetics, and would facilitate efforts to breed improved summer and winter squash cultivars. Random amplified polymorphic DNA (RAPD) markers were used to construct a partial map of the Cucurbita genome. The mapping population was the $\mathrm{BC}_{1}$ progeny of the Cucurbita pepo L. yellow straightneck inbred A0449 and the tropical Cucurbita moschata Duchesne ex Lam. landrace 'Nigerian Local'. A0449 was the recurrent parent. This cross was chosen because of the relatively greater economic importance of summer squash, traits of value to be introgressed from the $C$. moschata parent, and maximized genetic variation from the interspecific cross. The map contains 148 RAPD markers in 28 linkage groups. Loci controlling five morphological traits were placed on the map. The map covers $1,954 \mathrm{cM}$, which is estimated to be $75 \%$ of the $\mathrm{Cucurbita}$ genome. The qualitative traits placed on the map include the $B$ gene for fruit which turn yellow before anthesis, the $M$ gene for silver mottling of leaves, and a locus controlling the intensity of rind color on mature fruit. Quantitative trait loci (QTL) associated with fruit shape and the depth of the indentations between primary leaf veins were identified.
\end{abstract}

The Cucurbita pumpkins, squash and gourds are represented by five species that were domesticated in the Americas. Most widely grown in North America, C.pepo includes summer squash (yellow straightneck and zucchini types), Jack O' Lantern pumpkins, acorn and delicata winter squash, and small ornamental gourds. Various other winter squash types grown in North America belong to $C$. moschata, $C$. maxima, and $C$. argyrosperma, while C. ficifolia is grown almost exclusively in Latin America. The genetic improvement of this genus is complicated by the numerous types belonging to different species. In some cases, interspecific hybridization is possible, allowing transfer of desirable traits among species and types. Of greatest economic importance are the $C$. pepo summer squash types. $C$. pepo was apparently domesticated in two separate regions: the Mississippi river valley and central Mexico (Decker, 1988). The species lacks desirable genetic variation for disease and insect resistance found in species of more tropical origin - the C. moschata tropical pumpkins, for example.

Compared to other annual vegetable species, several attributes of Cucurbita complicate genetic improvement efforts. As alluded to above, there exists complexities of different types within a species, multiple centers of origin, and interspecific relationships. Another difficulty is that Cucurbita is expensive to breed relative to other annual vegetable crops because of space needs and a requirement for a long growing season for some materials. Current efforts are also limited by a lack of funding for the genetic improvement of crops of small economic importance. As with other vegetables, consumption of squash and pumpkins is increasing in North America because of the recognition that vegetables are important in a healthy diet (USDA National Agricul-

Received for publication 23 Jan. 2002. Accepted for publication 10 Apr. 2002. Oregon Agricultural Experiment Station technical paper no. 11860. This paper is a portion of a $\mathrm{PhD}$ dissertation submitted by R.N.B., who was supported by an ARCO Fellowship. We are grateful to Augie Gabert and Mark Hutton of Sunseeds, Brooks, Ore., for providing seed of the parental lines, and greenhouse space for the development of the mapping population, and to H.S. Paris of Newe Ya'ar Research Station, Ramat Yishay, Israel, for fruitful discussion of the genetics of fruit color in Cucurbita.

${ }^{1}$ Corresponding author. Email: myersja@bcc.orst.edu. ture Statistics Service, 1997). The Cucurbita can supply carbohydrates, soluble fiber and provitamin A from the flesh, and protein, vegetable oils and vitamin $\mathrm{E}$ from the edible seeds. To meet increased demand for squash and pumpkin cultivars, additional research is needed. A genetic map for Cucurbita would improve our knowledge of genetics, and would facilitate breeding efforts.

The development of molecular tools for use in breeding Cucurbita species is still in the early stages and lags behind the major vegetable crops as well as other Cucurbitaceae. All Cucurbita species have twenty pairs of relatively short chromosomes. This compares to seven pairs in cucumber (Cucumis sativus), eleven in watermelon (Citrullus lanatus), and twelve in melon (Cucumis melo). Most morphological traits in Cucurbita appear to be unlinked, and many markers are required to adequately map the genome.

The genus Cucumis contains the best-mapped species of the Cucurbitaceae. There are currently five published maps of melon, and three maps of cucumber, with multiple versions of each map (Baudracco-Arnas and Pitrat , 1996; Brotman et al., 2000; DaninPoleg et al., 1998; Kennard et al., 1994; Liou et al., 1998; Oliver et al., 2000; Park et al., 2000; Perin et. al., 2000; Serquen at al., 1997; Wang et al., 1997). Efforts are currently underway to merge the cucumber maps (Staub and Serquen, 2000) and the melon maps, and to do comparative mapping between the two species (Danin-Poleg et al., 2000). Two of the melon maps are essentially complete, with twelve linkage groups and an average distance of $<5 \mathrm{cM}$ between markers. The maps contain stable, sequence based markers such as RFLPs, microsatellites, and markers based on expressed sequences of known function, in addition to RAPD makers, AFLPs and morphological markers (Oliver et al., 2000; Perin et al., 2000). The most extensive cucumber map is that of Park et al. (2000). It is less complete than the melon maps, having twelve linkage groups instead of the seven expected.

No linkage map of any Cucurbita species existed prior to the development of molecular mapping. Weeden and Robinson (1986) used isozyme markers to build the first map of Cucurbita. It was based on the $\mathrm{F}_{2}$ of the cross C. maxima $\times$ C. ecuadorensis, and contained 11 isozyme loci in five linkage groups. Lee et al. (1995) 
developed a RAPD map of an $\mathrm{F}_{2}$ population of a $C$. pepo $\mathrm{x} C$. moschata interspecific hybrid. The map of Lee et al. (1995) was small, consisting of 28 markers in five linkage groups. No morphological traits or other types of markers were included on the map. The markers on their map were labeled arbitrarily, rather than following the standard practice of identifying the markers by the primer and the band size in base pairs. This prevents comparisons between their map and other Cucurbita maps. The map of Lee et al. (1995) was the only published molecular map of Cucurbita prior to this study.

The Cucurbita map presented here is intended as a framework to be built upon in further research as we seek to locate markers useful to breeders, determine the genetics of complex traits, and study evolution and species divergence in Cucurbita, and higherlevel divergence among the Cucurbitaceae.

\section{Materials and Methods}

Plant materials. The mapping population consisted of 162 $\mathrm{BC}_{1}$ individuals from a cross between $C$. pepo A0449 and $C$. moschata 'Nigerian Local'. A0449 is a summer squash, an elite inbred line of the yellow straightneck type, developed by Sunseeds (Morgan Hill, Calif.). 'Nigerian Local' is a tropical pumpkin landrace that has been widely used as a source of virus resistance. The initial cross A0449 x 'Nigerian Local' was made in the

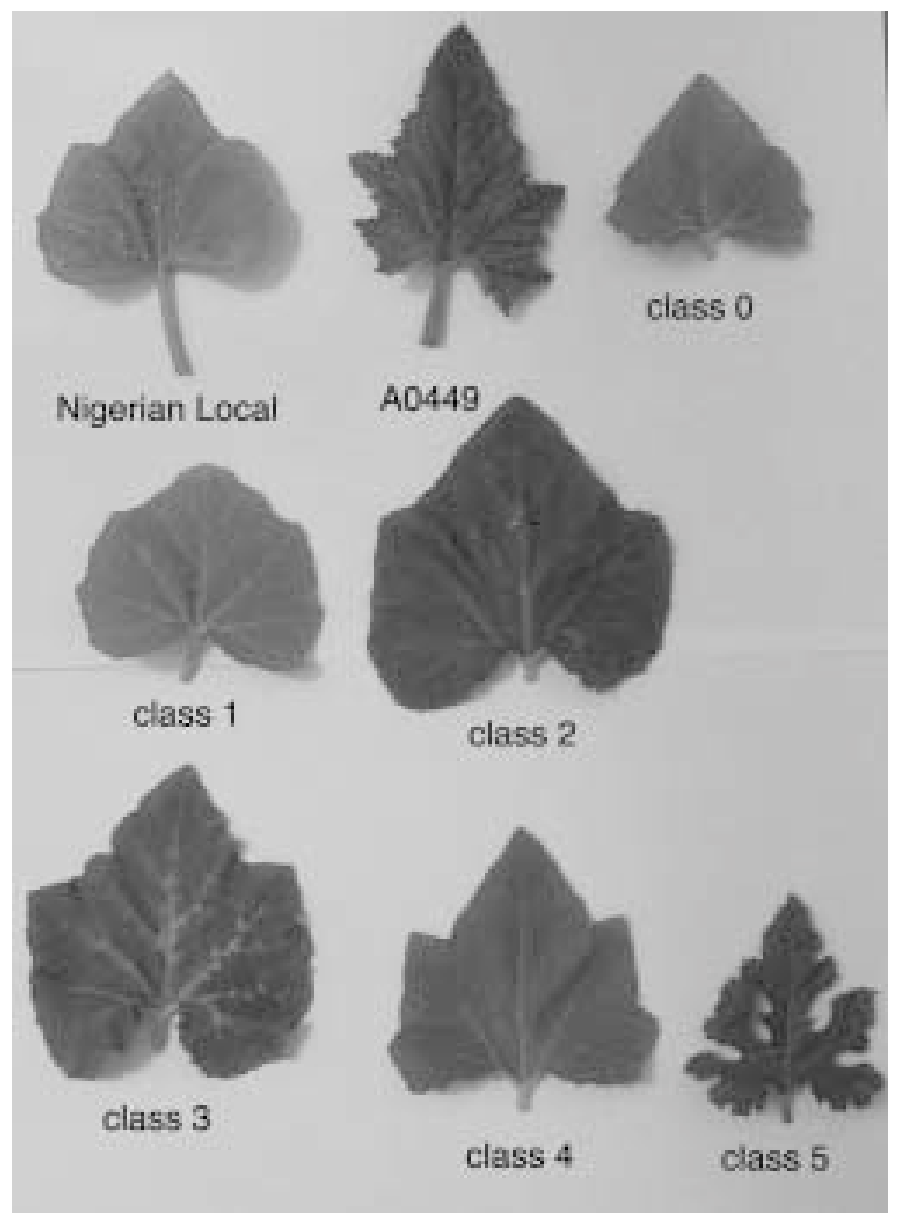

Fig. 1. Leaf indentation in the parents and $\mathrm{BC}_{1}$ mapping population. The leaf on the top left is from C. moschata 'Nigerian Local', the one in the top center is from $C$. pepo $\mathrm{A} 0449$, and the remaining leaves represent classes 0 to 5 used to score the $\mathrm{BC}_{1}$. greenhouse at Sunseeds in Brooks, Ore., in 1997. A single $F_{1}$ plant was obtained. The backcross population used in this experiment had $\mathrm{A} 0449$ as the female parent, and the $\mathrm{F}_{1}$ as the male.

The $\mathrm{BC}_{1}$ was seeded into $7.5-\mathrm{cm}$ pots in growth chambers on 19 Sept. 1999. When plants had one to two true leaves, the leaves were harvested for DNA extraction and the seedlings transplanted to 20 -L pots in the greenhouse. Plants were grown to maturity in the greenhouse. They were arranged in three rows running the length of each bench, with $\approx 10 \mathrm{~cm}$ between pots. All plants were staked to keep them upright, except for the 'Nigerian Local' plants, which were trellised. Temperatures ranged from 24 to $32{ }^{\circ} \mathrm{C}$; supplemental light ( $16 \mathrm{~h}$ day, $8 \mathrm{~h}$ night) was provided by high intensity metal halide and sodium vapor lights hung $1.3 \mathrm{~m}$ above the benchtop. The $\mathrm{BC}_{1}$ plants were hand-pollinated to produce fruit for data on fruit traits.

Morphological TRaITs. Leaf mottle was scored as the presence or absence of distinctive silver-white areas in the axils of the leaf veins. The extent of mottling varied both between plants and among the leaves of a given plant; the degree of variation was not examined.

Precocious yellow fruit is controlled by two genes, $B$ and $E p$. $B$ regulates the expression of the phenotype, while $E p$ controls the extent of expression. Both genes are incompletely dominant. Phenotypes for $B$ and $E p$ were scored on immature fruit at or before anthesis. Fruit pattern was scored as bicolor or solid yellow; the extent of yellow or green on the peduncle was rated using a four-point scale from solid green to solid yellow. The data for the two traits were combined and related to known genotypes using information in the literature (Shifriss, 1981; Shifriss and Paris, 1981). Two Ep loci have been identified in C. pepo, Ep-I and Ep-2 (Shifriss and Paris, 1981). The loci are phenotypically indistinguishable; we do not know which locus is present in A0449.

Mature fruit were examined visually to determine the rind color. Hue (orange, yellow, green, or tan) and intensity (light or dark) were recorded separately, as they have been shown to be controlled by different loci (Paris et al., 1985; Paris and Nerson, 1986). Hue and intensity were determined relative to the fruit of the parent lines and the other $\mathrm{BC}_{1}$ plants. No color chart was used.

The basic fruit shape in squash ranges from disc-shaped through round to elongate. The shape was quantified by measuring the length and width of mature fruits from closeup photographs. Length was measured from the point of peduncle attachment to the blossom scar, and width was measured across the widest point, perpendicular to the length axis. The measurement used in the genetic analysis was the length: width ratio, which was calculated by dividing the length by the width. This value was independent of actual fruit size or the scale of the photograph.

For the mapping population, the degree of indentation between the primary veins of the leaves was scored on a 0 to 6 scale, where $0=$ an entire leaf margin, and $6=$ deep indents between all lobes similar to the cut leaf trait in zucchini. The scale is illustrated in Fig. 1. The genetic control of leaf margin indentation is unknown in C. pepo or C. moschata, although it is controlled by a single recessive gene in $C$. maxima, which normally has an entire leaf margin (Dyutin, 1980).

DNA EXTRACTION. DNA was extracted using a modified CTAB (hexadecyl trimethyl ammonium boride) technique as described in Brown et al. (1998). Concentration was determined using a DNA fluorometer (Hoefer DyNA Quant 200; Pharmacia Biotech Inc., San Francisco, Calif.) according to the manufacturer's directions. The DNA was further purified by running $20 \mu \mathrm{g}$ of 
DNA from each sample through GeneMate PCRpure spin columns (ISC BioExpress, Kaysville, Utah) and reeluting with 50 $\mu \mathrm{L}$ of Tris buffer. The DNA stocks were diluted to $5 \mathrm{ng} \cdot \mu \mathrm{L}^{-1}$ in sterile ultrapure water to create working stocks for polymerase chain reaction (PCR).

Polymerase chain Reaction. DNA from the five plants representing each parental line was bulked, and these bulks were used to screen primers. Primers that amplified poorly on the first screening were screened a second time. Operon primer sets A through R (Operon Technologies, Inc., Alameda, Calif.) and University of British Columbia (UBC) primers 405, 411, 417, 419, 421, 423, 425, 430, 432, 447, 489, 533, 546, 550, 577, 589, 592, and 597 (Nucleic Acid-Protein Service Unit, Vancouver, B.C.) were used to screen the parents; those primers which had strong bands present in 'Nigerian Local' but not in A0449 were used to amplify the mapping population. Because the mapping population was the $\mathrm{BC}_{1}$ to inbred $\mathrm{A} 0449$, bands present in that parent did not segregate in the progeny. Reaction mixtures contained $30 \mathrm{ng}$ of plant genomic DNA, $1.5 \mathrm{mM} \mathrm{MgCl}_{2}, 0.1 \mathrm{~mm}$ dNTPs, 3 pmole of primer (Operon or UBC), 0.5 units of Taq DNA polymerase (Promega, Madison, Wis.), and $1 \times$ Taq buffer (Promega) in a total volume of $15 \mu \mathrm{L}$. The amplification program was $2 \mathrm{~min}$ at $94^{\circ} \mathrm{C}$ followed by 5 cycles of $5 \mathrm{~s}$ at $94^{\circ} \mathrm{C}, 1 \mathrm{~min}$ at $37^{\circ} \mathrm{C}, 30 \mathrm{~s}$ at $54^{\circ} \mathrm{C}$, a $7 \mathrm{~min}$ ramp to $72^{\circ} \mathrm{C}$, and $2 \mathrm{~min}$ at $72^{\circ} \mathrm{C}$, and then 30 cycles of $5 \mathrm{~s}$ at $94^{\circ} \mathrm{C}, 1 \mathrm{~min}$ at $37^{\circ} \mathrm{C}, 30 \mathrm{~s}$ at $54^{\circ} \mathrm{C}$, and $2 \mathrm{~min}$ at $72{ }^{\circ} \mathrm{C}$, ending with $15 \mathrm{~min}$ at $72^{\circ} \mathrm{C}$. Because of the size of the population, it was necessary to amplify the population in two batches for each primer. Parental and $\mathrm{H}_{2} \mathrm{O}$ controls were included in each batch. In the interest of speed, four thermocyclers [one MJR-100 (MJ Research, Cambridge, Mass.), one PE 9600, and two PE 9700s (PerkinElmer, Wellesley, Mass.)] were used. To minimize the effects of differences between machines, both batches for each primer were run on the same machine. In addition, the amplification profiles were adjusted to be as identical as possible on the four machines. The PCR products were separated on $1.5 \%$ agarose (Seakem LE; FMC, Rockland, Maine) or Ultrapure (Gibco, Grand Island, N.Y.)) in 0.5\% TBE buffer. PCR product molecular weight was determined with a 100-bp ladder (Promega). The gels were stained with ethidium bromide and recorded on Polaroid 667 film. Only strong, repeatable bands were scored.

DAta ANALYSIS. RAPD bands were scored as present or absent. Because the mapping population was a $\mathrm{BC}_{1}$, only bands present in 'Nigerian Local' and absent in A0449 showed segregation. Chi-square goodness of fit (Ramsey and Schafer, 1997) was used to test fit to the expected 1:1 segregation ratio.

The map was constructed in Mapmaker version 3.0 (Lincoln et al., 1992) using the Group, Compare, Try, and Ripple commands. Map order was double-checked using the Order command. A LOD score of 5.0 and a maximum recombination frequency of $30 \%$ were used to determine linkage groups. The higher LOD score was used to compensate for the lower genetic information present in a backcross population compared to an $\mathrm{F}_{2}$ population, and the inherent errors of present/ absent markers such as RAPD markers. However, lowering the LOD threshold for grouping to 4.0 or 3.0 resulted in no significant changes to the map. Lowering the maximum recombination frequency to $25 \%$ did not eliminate any markers which remained linked at $30 \%$ after the loci were placed in the most probable map order. The map itself is reported in Kosambi centimorgans. Loci for which distortion could be attributed to poor amplification or difficulty in scoring were discarded.

Morphological traits were scored in a variety of ways, depending on expression. For those traits where segregation appeared to fit a 1:1 segregation ratio, the morphological data were recoded by setting the phenotype of the yellow squash parent equal to 0 , and the 'Nigerian Local' or nonparental phenotype equal to 1. Leaf mottle, precocious yellow fruit, mature fruit color intensity and peduncle color were analyzed this way using Mapmaker. The relationship of quantitative traits to the mapped loci was analyzed using QTL Cartographer (Basten et al., 1999). The LOD threshold for each trait was calculated using the Permutations function with 150 iterations.

\section{Results and Discussion}

\section{Morphological traits}

LEAF MOTTLE. Leaves of A0449 are uniformly green, while some plants of 'Nigerian Local' have silvery-white mottling in the axils of the leaf veins. The silvering is caused by air spaces within the palisade cell layer and between that layer and the epidermis (Scarchuk and Lent, 1965), and is distinct from the leaf silvering caused by insect feeding. This mottling is controlled by a single dominant gene $(M)$ with an unknown number of modifiers in both $C$. moschata and $C$. pepo (Coyne, 1970; Scarchuk, 1954). The $\mathrm{BC}_{1}$ progeny contained some plants with silver-

Table 1. Segregation of qualitative morphological traits in the $\mathrm{BC}_{1}$ progeny of the cross Cucurbita pepo A0449 x (A0449 x C. moschata 'Nigerian Local'). Phenotype A is the phenotype of A0449 and Phenotype B is the phenotype of 'Nigerian Local' except where footnoted.

\begin{tabular}{|c|c|c|c|c|c|}
\hline \multirow[b]{2}{*}{ Trait } & \multicolumn{2}{|c|}{ Plants (no.) } & \multirow{2}{*}{$\begin{array}{c}\text { Expected } \\
\text { ratio }\end{array}$} & \multirow[b]{2}{*}{$\chi^{2}$} & \multirow[b]{2}{*}{$P$} \\
\hline & Phenotype A & Phenotype B & & & \\
\hline \multicolumn{6}{|l|}{ Leaf mottle } \\
\hline Peduncle color yellow ${ }^{z}$ vs. green & 82 & 73 & $1: 1$ & 0.52 & 0.47 \\
\hline Extended yellow solid color vs. bicolor ${ }^{y}$ & 83 & 72 & $1: 1$ & 0.78 & 0.38 \\
\hline Mature fruit color intensity & 43 & 54 & $1: 1$ & 1.25 & 0.26 \\
\hline
\end{tabular}

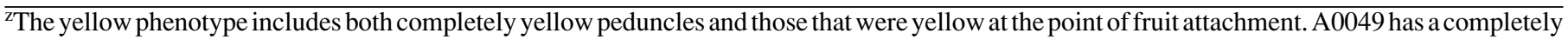
yellow peduncle.

${ }^{y}$ Solid includes both yellow fruit with yellow peduncle and yellow fruit with green peduncle. Bicolor includes bicolor fruit with green peduncles, and yellow fruit with bicolor peduncle. A0449 has yellow fruit and a yellow peduncle; the green fruit and peduncle of 'Nigerian Local' were not present in the $\mathrm{BC}_{1}$.

${ }^{x}$ Ratio expected for a complementary three-gene model where one gene (which alone does not intensify pigment expression) is required for expression of one or both of two other genes at independent loci. 
mottled leaves, indicating that the 'Nigerian Local' parent carried the dominant allele at $M$. The degree of mottling in the $\mathrm{BC}_{1}$ progeny ranged from one plant with completely silvered leaves to plants with only tiny silver patches in the axils of the primary veins. Mottling was scored as either present or absent, because the variation in degree of mottling was continuous, and changed from leaf to leaf within a plant. The ratio of mottled to plain leaves was 67:95, which differs from the expected single gene ratio at $P>$ 0.05 , but does not differ at $P>0.01$ (Table 1). Shifriss (1984) showed that the mottled phenotype is more fully expressed under conditions of high light intensity. The excess of plain-leafed plants may have resulted from the low light intensity in the greenhouse. The mottled leaf trait was mapped despite its distorted segregation, and was placed on linkage group 6 (Fig. 2).

LEAF INDENTATION. Plants of $C$. moschata normally have leaves with little to no indentation between the veins, while the leaves of $C$. pepo plants may be deeply indented (Whitaker and Davis, 1962). Sixty of the $\mathrm{BC}_{1}$ progeny had leaves that were more deeply indented than either parent, as shown in Fig. 3. A0449 has shallow indents on either side of the apical vein, which fits class 2 on the scale (Fig. 1). Most 'Nigerian Local' plants had very shallow indentations, fitting class 1 on the scale. This trait was somewhat difficult to classify, as the degree of indentation varied among leaves of a given plant. The distribution is typical of a quantitative trait. A significant QTL was identified on linkage group 5 between the marker loci F10_400 and G2_400, with the point of maximum likelihood at the locus K11_950 (Fig. 2). The LOD threshold was 12.59. The transgressive segregation seen in the mapping population suggests that two or more genes are involved, some of which may come from 'Nigerian Local'.

Fruit ShaPE. 'Nigerian Local' has round fruit, while A0449 has long, slightly flared fruit. The length: width ratios are 0.9 and 3.1, respectively (Fig. 4). The $\mathrm{F}_{1}$ had elongated pear-shaped fruit, and fruit shape in the $\mathrm{BC}_{1}$ ranged from the long shape of the recurrent parent through oval shapes to fruit nearly as round as that of 'Nigerian Local' (Fig. 4). Inheritance of fruit shape is known to be complex and multigenic, with elongated shapes sometimes being dominant and sometimes recessive (Sinnott and Hammond, 1930). Narrowing of the fruit at the peduncle end, resulting in a pear shape, appears to be inherited separately from the fruit length or width, in that pear shapes of all lengths occurred in the $\mathrm{BC}_{1}$, from short, nearly round pear shapes to long crookneck shapes. Round and round-pear shapes usually represent intermediate (heterozygous) conditions in C. pepo (Sinnot, 1922; Whitaker, 1932), but may not in C. moschata. A significant QTL for the length: width ratio was identified on linkage group 10 between the RAPD markers L19_800 and P19_400, with the point of maximum LOD at B8_900

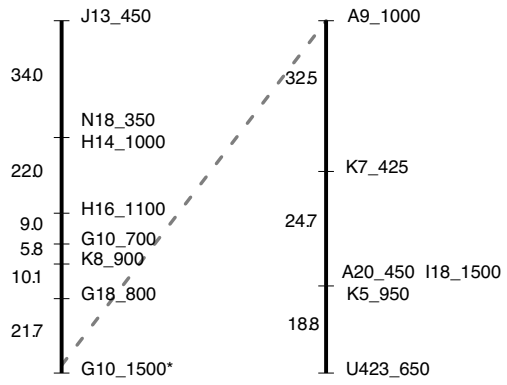

Group 3a

Group 3b

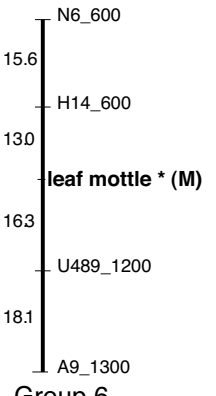

Group 6

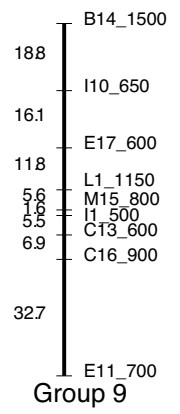

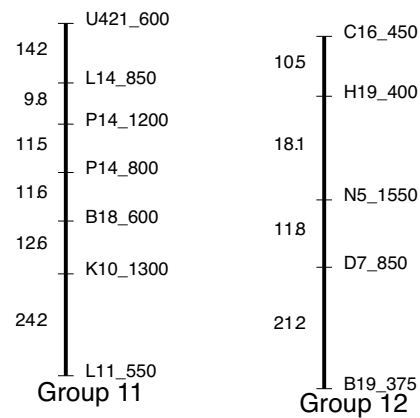

\section{西

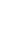

(Fig. 2). The LOD threshold was 10.09. Extensive studies of fruit resulting in long or wide fruit shapes, respectively (Sinnott and Durham, 1929). However, it is not clear how many genes control

Fruit RIND COLOR. Fruit rind color is probably the best-studied trait in C. pepo. At least eleven genes, two of them having more than two alleles, are involved. A0449 has yellow fruit from the also of genotype $Y / Y$ (Sinnot and Durham 1922). The peduncle and the base of the corolla are also yellow, indicating that A0449 carries at least two dominant Ep alleles. The Ep alleles are known; they are additive and incompletely dominant. The degree of extension of the precocious yellow phenotype depends on the number of dominant $E p$ alleles present, and on the genotype at $B$

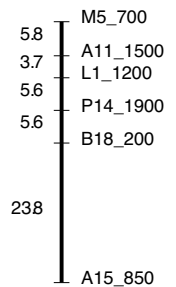

Group 1
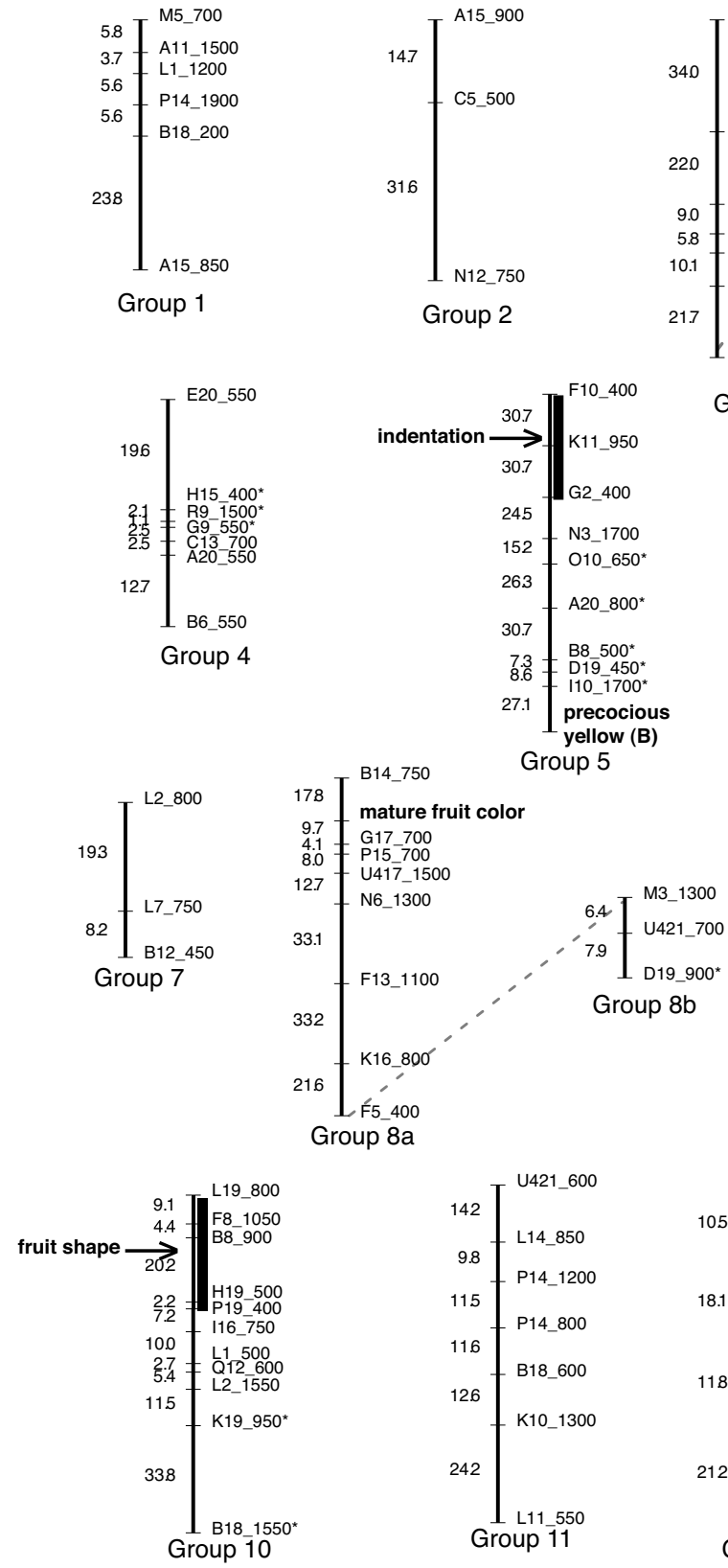

J. AMER. Soc. Hort. ScI. 127(4):568-575. 2002. 
$(B / B$ or $B / b)$. The $E p$ loci have no known effect on genotype $b / b$ (Shifriss and Paris, 1981). The 'Nigerian Local' parent had green immature fruit which ripened black-green with a green peduncle.

Immature fruit of plants in the $\mathrm{BC}_{1}$ generation segregated for bicolor vs. precocious yellow fruit. Peduncles segregated for green, bicolor yellow and green, and yellow. No fruits were completely green, indicating that $B$ was dominant over the color genes from 'Nigerian Local'. This agrees with the results of attempts to move $B$ from $C$. pepo to $C$. moschata (Paris et al., 1986). About $25 \%$ of the fruit were bicolored, indicating that they

Fig. 2. Linkage map of the backcross Cucurbita pepo A0449 x (A0449 x C. moschata 'Nigerian Local'). The map was constructed using a LOD of 5.0 and a maximum of $30 \%$ recombination. Groups marked $a$ and $b$ were linked according to Mapmaker, but when the loci are placed in the best order, the groups are separated by $>36 \mathrm{cM}$. RAPD markers are identified by primer and approximate size in base pairs. Those beginning with A-R = Operon primers; $\mathrm{U}$ $=$ UBC primers. "Marker was significantly distorted from the expected $1: 1$ segregation. The positions of QTL are indicated by vertical bars next to the group backbone.
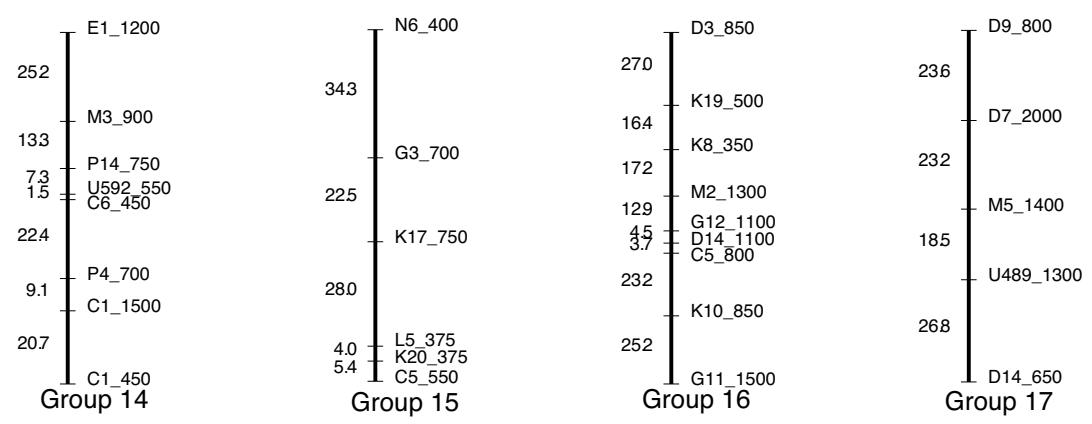
(Table 2). Another $25 \%$ of the plants had yellow peduncles as well as uniformly yellow fruits like A0449, suggesting that they were homozygous for $B$ and for the $E p$ gene (Table 2). Of the remaining $50 \%$, half had a thin band of yellowing where the peduncle joined the fruit, indicating that they were homozygous for $B$ but had only one Ep allele (Shifriss and Paris, 1981). The others had uniformly green peduncles and were presumably heterozygous for $B$ but carried two $E p$ alleles (Table 2). The segregation fit the 1:1:1:1 ratio expected for a two-gene model in the backcross to the parent carrying the dominant alleles. If contrasting phenotype classes were compared, both $B$ and $E p$ fit the single gene model (Table 1). The $B$ gene has been placed at one end of linkage group 5; the $E p$ gene present in A0449 remains unlinked (Fig. 2).

Mature fruit colors ranged from orange through the golden yellow of A0449 to plain yellow and dull yellow-tans to greenish yellows. Fruit color intensity was independent of $B$ in that bicolor fruit occurred in both light and intense colors. If plants were separated into those bearing intensely colored fruit (orange or golden yellow) like A0449, and those bearing lightercolored fruit (yellow, yellow-tan, and greenish yellow) the data fit both a one-gene model and a threegene model (Table 1). If the one-gene model is accepted, then the segregating gene is most likely an unidentified dominant factor from 'Nigerian Local' that decreases the intensity of rind color associated with $B$, but has no effect in a $b b$ background. Such a factor was observed in the black-fruited $C$. moschata PI 165561, but was not explored further (H.S. Paris, personal communication). Segregation of $L-1$ from 'Nigerian Local' would also result in a ratio of 1 intense : 1 light for rind color, but in that case A0449 should have had light-colored fruit. Intensely-colored fruit versus light-colored fruit was mapped to linkage group $8 \mathrm{a}$, but the identity of the locus is unclear.
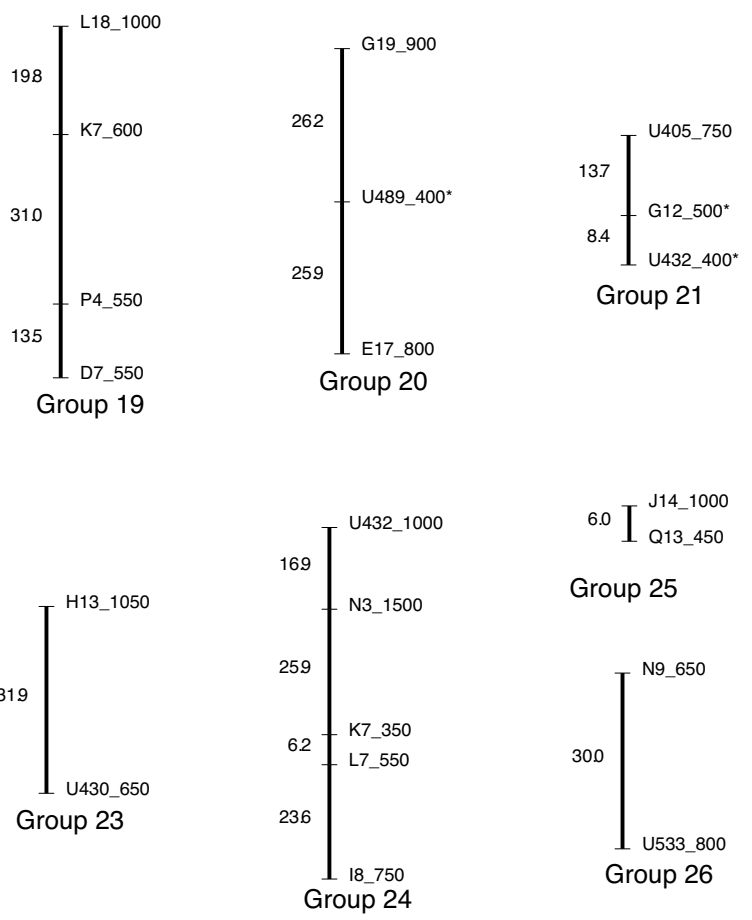

6.0 I14_1000

Group 25

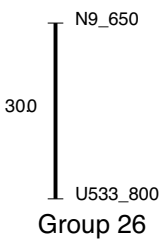

\section{RAPD markers}

A total of 378 primers were screened on the parental bulks; 72 failed to amplify clear bands in one or both parents, even when repeated. Of the remaining 306 primers, 162 (52.9\%) amplified bands that were polymorphic in 'Nigerian Local' and distinct from bands in A0449. In total, 212 bands were scored, 175 of which were included in the data set for map construction. The remaining 37 bands were discarded because of nonbiological segregation distortion or questionable scoring. In total, 148 RAPD markers were placed on the map. All of the RAPD markers amplify DNA sequences from 'Nigerian Local', so are linked in repulsion to alleles controlling traits in A0449.

\section{The map}

The map contains 151 loci: 148 RAPD markers and 3 morphological marker loci. There are 28 linkage groups (Fig. 2); the haploid genome of Cucurbita contains 20 chromosomes. Two pairs of linkage groups, $3 \mathrm{a}$ and $3 \mathrm{~b}$ and $8 \mathrm{a}$ and $8 \mathrm{~b}$, are considered to be single linkage groups by Mapmaker at LOD 5 and a maximum of $30 \%$ recombination, but when the loci are arranged in the best possible order they are more 


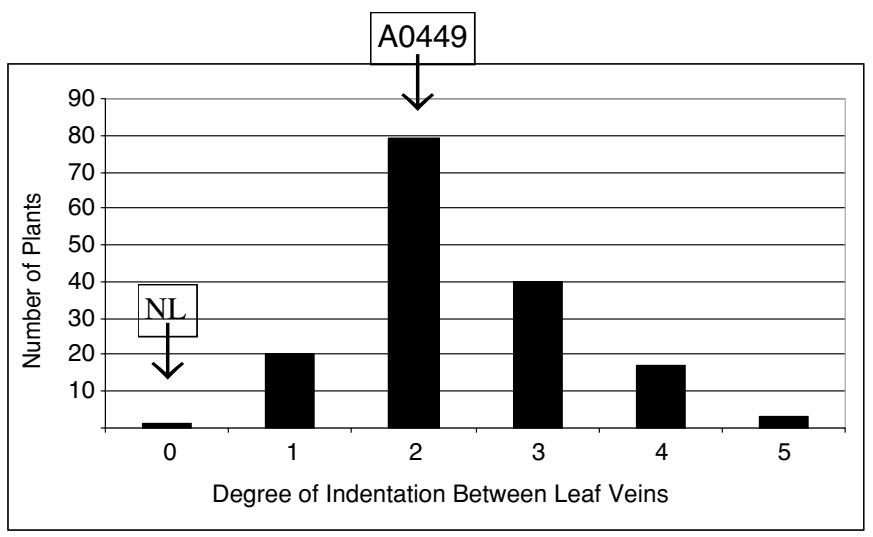

Fig. 3. The distribution of indentation between the primary leaf veins in the progeny of the cross Cucurbita pepo A0449 $\times$ (A0449 $\times$ C. moschata 'Nigerian Local'). The scale used to rate the leaves is shown in Fig. 1.

than $36 \mathrm{cM}$ apart. The map covers a total of $1,954 \mathrm{cM}$ with an average of $12.9 \mathrm{cM}$ between loci. However, the loci are not evenly distributed, so many gaps are more than $20 \mathrm{cM}$. Two QTL have been identified, one influencing fruit shape and the other influencing leaf indentation. In addition to the 28 linkage groups included here, nine RAPD markers and one qualitative locus remain unlinked.

This Cucurbita map is much more complete than that of Lee et al. (1995), which contained only 28 RAPD markers in 5 linkage groups. The Cucumis melo map of Perin et al. (2000), the most comprehensive map in the Cucurbitaceae, covers $1590 \mathrm{cM}$ and is believed to cover the 12 chromosomes of melon in their entirety. The $1,981 \mathrm{cM}$ of this map cover approximately $75 \%$ of the Cucurbita genome. However, significant gaps remain to be filled on this map.

The segregation at 21 loci placed on the map differed significantly from the expected 1:1 ratio. One of these loci was the mottled leaf trait; the excess of plain-leaved plants may be due to the low light intensity under which the plants were grown. The other distorted loci were RAPD markers. Five linkage groups contained more than one distorted marker. In all cases the distorted markers were grouped together.

Distorted segregation ratios in segregating populations can arise from competition among gametes during fertilization, which is a result of gametophyte genes expressed in the haploid genotype. Distorted segregation can also be a result of hybrid sterility genes causing the abortion of certain genotypes (Faris et al., 1998). Lethal and sublethal genes can also result in segregation distortion if they result in embryos that are too weak to germinate properly, or plants that die before maturity. Distortions can also be caused by unequal crossing over and chromosome mispairing during meiosis. This is frequently a problem in interspecific crosses, and is one reason for their generally lower fertility. The synteny of the genomes of $C$. pepo and C. moschata is not known.

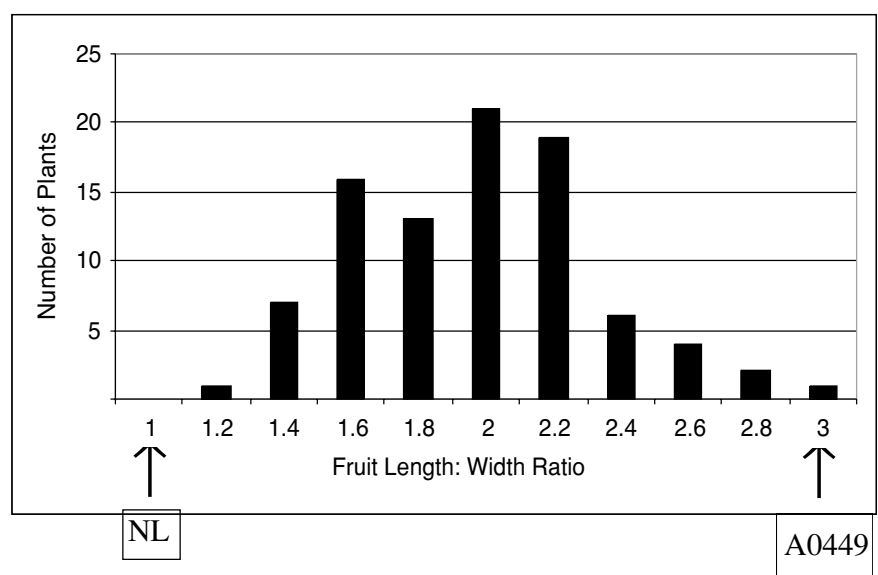

Fig. 4. The distribution of fruit shape in the cross C. pepo A0449 $\times(\mathrm{A} 0449 \times C$. moschata 'Nigerian Local'). Fruit shape is expressed as the ratio of fruit length to fruit width. 'Nigerian Local' has round fruit (ratio $=0.9$ ) and A0449 has elongate fruit (ratio $=3.1)$.

However, it is much more difficult to obtain viable seed with the interspecific crosses than with intraspecific crosses in either species.

It is of course always possible that distorted segregation can be random, or that it can be caused by errors in amplification and scoring. Problems with inconsistent amplification and scoring are common with RAPDs, where a null allele is not necessarily a reflection of a single gene sequence, and bands of the same size may not have the same sequence. Twelve of the distorted markers were distorted in the direction of A0449, with an excess of null alleles. This included the clusters of distorted markers on linkage groups 4, 5, and 21 . The remaining 10 markers, including the cluster on groups 10 and 18, were distorted in the direction of 'Nigerian Local', such that significantly more individuals had a band present.

Loci influencing five morphological traits were placed on the map. Only two of them have been identified as specific known genes in Cucurbita: Mottle leaf $(M)$ and precocious yellow $(B)$. For $B$, the band at $1700 \mathrm{bp}$ amplified by Operon primer I10 is 27.1 $\mathrm{cM}$ from the recessive allele from 'Nigerian Local'. Whether this marker will be of use to breeders will depend largely on whether there is enough similarity in the region surrounding $B$ in $C$. moschata and $C$. pepo that the linked RAPD bands will amplify and remain linked to the recessive allele in C. pepo. A marker for $B$ could be useful for transferring the precocious yellow phenotype into populations, and for maintaining that phenotype when transferring traits from nonprecocious yellow donors into precocious yellow populations. Such a marker would permit selection against the recessive allele in seedlings. The precocious yellow phenotype does not become apparent until plants begin developing female flower buds. This marker is too distant from the $B$ locus to be useful in marker-aided selection. However, it can

Table 2. Immature fruit color in the $\mathrm{BC}_{1}$ of the cross Cucurbita pepo A0449 x (A0449 x C. moschata 'Nigerian Local') segregated into four classes depending on the genotypes at the $B$ and $E p$ loci.

\begin{tabular}{lll}
\hline \hline Genotype & Phenotype & \\
\hline BBEpEp & Solid yellow with a completely yellow peduncle & 32 \\
BBEpep & Solid yellow with a mostly green peduncle; a thin yellow band at fruit attachment \\
BbEpEp & Solid yellow with a completely green peduncle & 50 \\
BbEpep & Bicolor green and yellow with a solid green peduncle & 40 \\
& & 33
\end{tabular}

$\chi^{2}=5.60, P=0.13$

${ }^{\mathrm{z} F i t}$ to a two-gene model with ratio of $1: 1: 1: 1$. 
serve as a reference point for identifying markers closely linked to the $B$ locus.

A dominant allele from $C$. moschata was mapped for the $M$ locus. Mottled leaves are found in many species of Cucurbita, and the same gene symbol has been assigned for C.pepo, C. moschata, and $C$. maxima. However, it is not entirely certain that the genes are allelic in all three species. Wessel-Beaver (personal communication) has indicated to R.N. Brown that further research failed to substantiate the linkage.

The mapping population segregated for many other traits in addition to the ones discussed above. Methods and data for these traits are discussed in detail in Brown (2001). Some of the traits could be traced to the action of known single genes; others were genetically more complex or have not been studied. Traits which appeared to be controlled by a single dominant gene included orange vs. pale fruit flesh, warty vs. smooth fruit, soft vs. stiff leaf hairs, rounded vs. pointed leaf lobes, and the development of foliar mosaic after inoculation with zucchini yellow mosaic virus. None of these traits were linked to any of the RAPD markers identified. Additional quantitative traits for which data were collected included the number of days from planting to first flower, the node at which the first flower was located, average internode length, response to powdery mildew, and virus titer in young tissue $28 \mathrm{~d}$ after inoculation with zucchini yellow mosaic virus. A0449 is resistant to powdery mildew; under severe disease pressure some sporulation occurs but no chlorosis or necrosis develops. A0449 is fully susceptible to zucchini yellow mosaic virus. 'Nigerian Local' is highly susceptible to powdery mildew, with extensive sporulation, chlorosis, and necrosis even under light disease pressure. It is entirely resistant to zucchini yellow mosaic virus, showing no symptoms and no detectable virus even after repeated inoculations. 'Nigerian Local' is a vine squash, with long internodes; it flowered 10 to 12 weeks after planting. A0449 is a compact bush, with extremely short internodes. It flowered $\approx 5$ weeks after planting (Brown, 2001). QTLs were identified for response to powdery mildew and for the number of days from planting to first flower. However, they were of borderline significance. No QTLs were identified for the other traits examined.

The map presented here represents a starting point for the construction of high-density maps in Cucurbita. More markers are needed to increase saturation, to complete the coverage of the genome and to permit the construction of a true framework map with markers evenly distributed throughout the genome. The map needs to be anchored with markers that are not populationspecific, such as simple sequence repeats (SSRs) or RFLPs. No SSRs or RFLPs are available specifically for Cucurbita. SSRs have been identified and primers developed for melon and cucumber (Danin-Poleg et al., 2001) and watermelon (Jarret et al., 1997). Small scale analysis of Cucurbita pepo genotypes using primers for 50 Cucumis SSRs found that seven (14\%) were functional and polymorphic (Katzir et al., 2000). However, it will probably be necessary to develop SSRs specific to Cucurbita to identify sufficient markers to fully anchor the map. More morphological traits are needed, particularly traits specific to C.pepo. Markers need to be more tightly linked to the morphological traits, and longer, more specific primers need to be developed for best results in marker-aided selection. Better characterization of the parental genotypes and the development of additional populations would also assist in adding morphological traits to the map. In particular, a map that could be used in breeding zucchini-type $C$. pepo cultivars would be of interest to the vegetable seed industry. The population used to construct this map was well suited to mapping in that the parents were morphologically quite disparate. However, 'Nigerian Local' is of interest only as a source of virus resistance, and yellow squash are economically important only in the southeastern United States.

\section{Literature Cited}

Basten, C.J., B.S. Weir, and Z.-B. Zeng. 1999. QTL Cartographer. http:/ /statgen.ncsu.edu/qtlcart/cartographer.html

Baudracco-Arnas, S. and M. Pitrat. 1996. A genetic map of melon (Cucumis melo L.) with RFLP, RAPD, isozyme, disease resistance and morphological markers. Theor. Appl. Genet. 93:57-64.

Brotman, Y., L. Silberstein, I. Kovalski, J. Klinger, G. Thompson, N. Katzir, and R. Perl-Treves 2000. Linkage groups of Cucumis melo, including resistance gene homologues and known genes. Acta Hort. 510:441-448.

Brown, R.N., J.R. Myers, M. Hutton, and P. Miller. 1998. A simple protocol for isolating DNA from fresh Cucurbita leaves. Cucurbit Genet. Coop. Rpt. 21:46-47.

Brown, R.N. 2001. Traditional and molecular approaches to zucchini yellow mosaic virus in Cucurbita. PhD thesis. Ore. State Univ., Corvallis.

Coyne, D.P. 1970. Inheritance of mottle-leaf in Cucurbita moschata Poir. HortScience 5:226-227.

Danin-Poleg, Y., N. Reis, S. Baudracco-Arnas, M. Pitrat, J.E. Staub, M. Oliver, P. Arus, C.M. deVicente, and N. Katzir. 2000. Simple sequence repeats in Cucumis mapping and map merging. Genome 43:963-974. Danin-Poleg, Y., N. Reis, G. Tzuri, and N. Katzir. 2001. Development and characterization of microsatellite markers in Cucumis. Theor. Appl. Genet. 102:61-72.

Danin-Poleg, Y., N. Reis, G. Tzuri, and N. Katzir. 1998. Simple sequence repeats as reference points in Cucumis mapping, p. 349-353. In: J.D. McCreight (ed.). Cucurbitaceae '98. ASHS Press, Alex., Va. Decker, D.S. 1988. Origin(s), evolution, and systematics of Cucurbita pepo (Cucurbitaceae). Econ. Bot. 42:4-15.

Dyutin, K.E. 1980. Spontaneous mutant of Cucurbita maxima Duch. squash with lobed leaves (in Russian). Genetika 16:176-178.

Faris, J.D., B. Laddomada, and B.S. Gill. 1998. Molecular mapping of segregation distortion loci in Aegilops tauschii. Genetics 149:319327.

Jarret, R.L., L.C. Merrick, T. Holms, J. Evans, and M.K. Aradhya. 1997. Simple sequence repeats in watermelon (Citrullus lanatus (Thunb.) Matsum \& Nakai). Genome 40:433-441.

Katzir, N., Y. Tadmor, G. Tzuri, E. Leshzeshen, N. Mozes-Daube, Y. Danin-Poleg, and H.S. Paris. 2000. Further ISSR and preliminary SSR analysis of relationships among accessions of Cucurbits pepo. Acta Hort. 510:433-439.

Kennard, W.C., K. Poetter, A. Dijkhuizen, V. Meglic, J.E. Staub, and M.J. Havey. 1994. Linkages among RFLP, RAPD, isozyme, disease resistance and morphological markers in narrow and wide crosses of cucumber. Theor. Appl. Genet. 89:42-48.

Lee, Y.H., H.J. Jeon, K.H. Hong, and B.D. Kim 1995. Use of random amplified polymorphic DNAs for linkage group analysis in interspecific hybrid $\mathrm{F}_{2}$ generation of Cucurbita. J. Kor. Soc. Hort. Sci. 36:323330.

Lincoln, S.E., M.J. Daly, and E.S. Lander. 1992. Mapmaker version 3.0. Whitehead Inst., Cambridge, Mass.

Liou, P.C., Y.M. Chang, W.S. Hsu, Y.H. Cheng, H.R. Chang, and C.H. Hsiao. 1998. Construction of a linkage map in Cucumis melo L. using random amplified polymorphic DNA markers. Acta Hort. 461:123131.

Oliver, M., J. Garcia-Mas, M. Morales, R. Dolcet-Sanjuan, M.C. de Vicente, H. Gomez, H. van Leeuwen, A. Monfort, P. Puigdomenech, and P. Arus. 2000. The Spanish melon genome project: Construction of a saturated genetic map. Acta Hort. 510:375-378.

Paris, H.S. and H. Nerson. 1986. Genes for intense fruit pigmentation of squash. J. Hered. 77:403-409. 
Paris, H.S., H. Nerson, and N. Zass. 1986. Effects of gene $B$ in Cucurbita moschata. HortScience 21:1036-1037.

Paris, H.S., H. Nerson, Z. Karchi, and Y. Burger. 1985. Inheritance of light pigmentation in squash. J. Hered. 76:305-306.

Park, Y.H., S. Sensoy, C. Wye, R. Antonise, J. Peleman, and M.J. Havey. 2000. A genetic map of cucumber composed of RAPDs, RFLPs, AFLPs, and loci conditioning resistance to papaya ringspot and zucchini yellow mosaic viruses. Genome 43:1003-1010.

Perin, C., L. Hagen, C. Dogimont, V. de Conto, L. Lecomte, and M. Pitrat. 2000. Construction of a reference genetic map of melon. Acta Hort. 510:367-374.

Ramsey, F.L. and D.W. Shafer. 1997. The statistical sleuth. Duxbury Press, Belmont, Calif. p. 545.

Scarchuk, J. 1954. Fruit and leaf characters in summer squash. J. Hered. 45:295-297.

Scarchuk, J. and J.M. Lent. 1965. The structure of mottle-leaf summer squash. J. Hered. 56:167-168.

Serquen, F.C., J. Bacher, and J.E. Staub. 1997. Mapping and QTL analysis of horticultural traits in a narrow cross in cucumber (Cucumis sativus L.) using random-amplified polymorphic DNA markers. Mol. Breed. 3:257-268.

Shifriss, O. 1981. Origin, expression and significance of gene $B$ in Cucurbita pepo L. J. Amer. Soc. Hort. Sci. 106:220-232.

Shifriss, O. 1984. Further notes on the silvery-leaf trait in Cucurbita. Cucurbit Genet. Coop. Rpt. 7:81-83.

Shifriss, O. and H.S. Paris. 1981. Identification of modifier genes affecting the extent of precocious fruit pigmentation in Cucurbita pepo L. J. Amer. Soc. Hort. Sci. 106:653-660.

Sinnott, E.W. 1922. Inheritance of fruit shape in Cucurbita pepo. Bot. Gaz. 74:95-103.

Sinnott, E.W. and D. Hammond. 1930. Factorial balance in the determination of fruit shape in Cucurbita. Amer. Nat. 64:509-524.

Sinnott, E.W. and G.B. Durham. 1922. Inheritance in the summer squash. J. Hered. 13:177-186.

Sinnott, E.W. and G.B. Durham.. 1929. Developmental history of the fruit in lines of Cucurbita pepo differing in fruit shape. Bot. Gaz. 87:411-421.

Staub, J.E. and F.C. Serquen. 2000. Towards an integrated linkage map of cucumber: Map merging. Acta Hort. 510:357-366.

USDA National Agriculture Statistics Service. 1997. Census of agriculture. USDA Natl. Agr. Stat. Serv., Wash., D.C.

Wang, Y.H., C.E. Thomas, and R.A. Dean. 1997. A genetic map of melon (Cucumis melo L.) based on amplified fragment length polymorphism (AFLP) markers. Theor. Appl. Genet. 95:791-798.

Weeden, N.F. and R.W. Robinson. 1986. Allozyme segregation ratios in the interspecific cross Cucurbita maxima $\mathrm{x} C$. ecuadorensis suggest that hybrid breakdown is not caused by minor alteration in chromosome structure. Genetics 114:593-609.

Whitaker, T.W. 1932. Fertile gourd-pumpkin hybrids. J. Hered. 23:427430.

Whitaker, T.W. and G.D. Davis. 1962. Cucurbits. Interscience Publ., New York. p. 46-48. 